\title{
EL MAL DE ESPAÑA: PARODIA DE LA VISIÓN ORGANICISTA DE LA NACIÓN EN TIEMPO DE SILENCIO, DE LUIS MARTÍN SANTOS
}

Después de transcurrido casi medio siglo desde la publicación de Tiempo de silencio (1962) de Luis Martín Santos, esta novela se ha convertido en una obra canónica de la narrativa española contemporánea. Los numerosos estudios críticos que se han dedicado a Tiempo de silencio examinan diversos aspectos semióticos, estructurales, estéticos, filosóficos y sociológicos: realismo dialéctico, elementos míticos y simbólicos, alusiones intertextuales (El Quijote de Cervantes, Ulisses de Joyce), afinidades estéticas (Goya, Valle-Inclán, Kafka, Faulkner) y filosóficas (espíritu reformista del 98, Ortega y Gasset, Sartre). Se ha estudiado también en profundidad el violento contraste que hay entre una temática que subraya la conciencia del subdesarrollo de la España de la posguerra y una forma que muestra los modelos narrativos y culturales del desarrollo: rasgos neobarrocos, elaboración verbal, cultismos y técnicas narrativas experimentales.

Otros críticos han explorado lecturas alegóricas del cáncer y la enfermedad en Tiempo de silencio. En "Mitos órficos y cáncer social" , Ricardo Gullón hace alusión a una conexión metafórica que no puede ser obviada: el cáncer, objeto de investigación del protagonista, tiene un significado literal y otro figurado (p. 80). Gullón apunta, pero no desarrolla en profundidad, los términos de la alegoría que Martín Santos presenta en Tiempo de silencio al establecer una red de conexiones, explícitas e implícitas, entre la enfermedad física del cuerpo individual y la del cuerpo social. Una década más tarde, Gustavo Pérez Firmat retoma la metáfora del cáncer para describir el estilo "proliferante, exce-

${ }^{1}$ El Urogallo, 17 (1972), 80-89. 
sivo y reiterativo" del texto ${ }^{2}$. Para Pérez Firmat el acto creativo en Tiempo de silencio se asocia a la existencia de una sustancia "pregnante", una especie de "supersemen" (Matías cuando ve el cuadro del artista alemán dice que no tiene "magma") y termina afirmando que para Martín Santos escribir es "eyacular un tumor" (p. 196). La conexión entre escritura y enfermedad vuelve a aparecer en el ensayo de Gustavo Faverón Patriau ${ }^{3}$, cuyo planteamiento toma como punto de partida la idea de que el cáncer funciona no sólo a nivel denotativo y metafórico, sino que también se convierte en elemento omnipresente del relato, cuya realidad representa

un gran objeto único, compuesto (y no precisamente habitado) por una enormidad de microorganismos pululantes, con lo cual ceden las fronteras salvadoras de la representación de la enfermedad como realidad ajena y se plantea, más bien, la infección generalizada, la metástasis total, como elemento organizador del mundo representado (p. 80).

En este ensayo ahondo en la lectura metafórica del cáncer, pero enfocándome en la alegoría del "mal de España" y la parodia que Martín Santos hace de las teorías regeneracionistas y organicistas de los ensayistas finiseculares. Así pues, el complejo entramado de "metáforas orgánicas" que aparece en esta obra no sólo refleja la preparación académica y profesional de Martín Santos en el campo de la medicina, sino más bien la huella de ensayistas y filósofos como Joaquín Costa ${ }^{4}$, Ángel Ganivet (Idearium español), Miguel de Unamuno (En torno al casticismo) y José Ortega y Gasset (La España invertebrada $)^{5}$.

2 "Repetition and excess in Tiempo de silencio", PMLA, 96 (1981), pp. 194209.

3 "La máquina de hacer muertos: enfermedad y nación en Tiempo de silencio de Luis Martín-Santos", Colorado Review of Hispanic Studies, 1 (2003), 79-90.

${ }^{4}$ Política quirúrgica, Biblioteca Costa, Madrid, 1914; Oligarquía y caciquismo. Colectivismo agrario y otros ensayos, Alianza, Madrid, 1969.

${ }^{5}$ Sobre la influencia de los escritores de la generación de fin de siglo en Luis Martín Santos y el reflejo de su pensamiento en Tiempo de silencio, véanse Fernando Morán, Novela y semidesarrollo, Taurus, Madrid, 1971; José Carlos Mainer, "Luis Martín Santos, de Tiempo de silencio a Tiempo de destrucción", en "Tiempo de silencio" de Luis Martín-Santos, "Señas de identidad" de Juan Goytisolo: Deux romans de la rupture?, Université de Toulouse-Le Mirail, Toulouse, 1980, pp. 53-65; Jo LABANy I, Ironía e historia en "Tiempo de silencio", Taurus, Madrid, 1985; Thomas R. Franz, "Baroja's 'Science' in Martín Santos's 'Time”", H, 66 (1983), 324-332; Carlos JerEz-Farrán, “"Ansiedad 
Tiempo de silencio, tan radicalmente original en aspectos estructurales y lingüísticos, no lo es en la aplicación del diagnóstico clínico a la nación. Las teorías organicistas han sido usadas tanto por la derecha como por la izquierda para apoyar sus respectivas bases ideológicas. El cuerpo y las enfermedades nos remiten, de forma alegórica, a la dinámica del cuerpo político. Ante la crisis sociopolítica que se produce en España a finales del siglo XIX a raíz de la pérdida de las últimas colonias, un grupo de intelectuales españoles ofrece un diagnóstico y se propone superar la crisis proponiendo una cura para el mal que sufre la nación. Pero antes de que estos intelectuales comenzaran a tener visibilidad en la España finisecular, en los círculos políticos se había empezado a hablar ya de "regeneracionismo". En biología, la regeneración consiste en la reconstrucción de las partes dañadas de un organismo vivo. La representación metafórica de la nación como un cuerpo enfermo y decadente que puede ser sanado mediante la regeneración de los órganos afectados constituye el planteamiento inicial de estos intelectuales finiseculares, quienes llevan a cabo una detallada radiografía de la nación para detectar las causas del fracaso y para proponer una España nueva que debía resurgir recuperando las propias raíces.

El discurso que se desarrolla en torno al "mal de España" se deriva y está en consonancia con la filosofía organicista europea, que alcanza su auge en el siglo xix. En Alegorías de la voluntad $^{6}$, Francisco La Rubia Prado explica que el organicismo es una visión del mundo "fuertemente arraigada en la tradición cultural de Occidente" (p. 29) cuyos orígenes se remontan a Platón ( $\mathrm{El} \mathrm{Fedro)} \mathrm{y} \mathrm{a} \mathrm{Aristóteles} \mathrm{("el} \mathrm{todo} \mathrm{es} \mathrm{anterior} \mathrm{a} \mathrm{las} \mathrm{par-}$ tes"). El organicismo es una filosofía cuyas categorías se derivan metafóricamente del cuerpo humano como una unidad cuyas

de influencia» versus intertextualidad autoconsciente en Tiempo de silencio de Martín-Santos", Symposium, 42 (1988), 119-132 y C.A. Longhurst, "Luis Martín-Santos y el 98: ¿Tiempo de corrección?”, HR, 74 (2006), 279-300. A pesar de que LONGHURST opina que Tiempo de silencio es "un homenaje a unos ilustres predecesores, y nunca una reconvención” (p. 299), me inclino, con Jo LABANYi, a hacer una lectura paródica de esta novela. JerEz-FARRÁn, a su vez, piensa que Luis Martín Santos, "consciente de la deuda que contrae con su precursor, hace un esfuerzo deliberado por escamotear su presencia" (p. 129). MoRÁn fue el primero en observar la intertextualidad entre El árbol de la ciencia de Pío Baroja y Tiempo de silencio; Franz y Longhurst ahondan en el análisis intertextual.

${ }^{6}$ Libertarias-Prodhufi, Madrid, 1996. 
partes no pueden funcionar por separado, sino de forma interdependiente. La Rubia Prado lo define como:

una visión del mundo, o metafísica, en la que el todo no sólo es más que la suma de las partes, sino que las precede; las partes, desde siempre, afirma el organicista, han pertenecido a la totalidad orgánica, y toda apariencia contraria a esta verdad fundamental no es sino una ilusión. La realidad, la verdadera realidad, es la que nos ofrece la visión totalizadora de la unidad orgánica, previa a la individualización de sus componentes, pero que, a la vez, permite a esos componentes una individualización real dentro de la colectividad (pp. 15-16).

El organicismo, en su equiparación cuerpo-sociedad, pone énfasis en la unidad, en vez de considerar a los individuos en su multiplicidad. Werner Stark distingue dos tipos de organicismo. El primero es el positivista, que considera que el orden social es un organismo y que por lo tanto el cuerpo social sigue las mismas leyes del cuerpo físico. El segundo es el normativo y plantea que la sociedad está diseñada como un organismo, pero dicho diseño no necesariamente se hace realidad. En otras palabras, el diseño es orgánico, pero no siempre hay armonía entre la estructura que emerge en la sociedad y el patrón orgánico de base. Stark lo resume en los siguientes términos:

Society, fundamentally an organic system, should become so in the full sense of the word. Positive organicism is restricted to the Is; normative organicism distinguishes an Is and an Ought, yet the Ought is not really, or radically, at variance with the Is. Rather is its true working out, its natural realization. It is more than an idle play upon words to say, that the normative theory demands that society should become what it is-that it should become in reality what it is in design ${ }^{7}$.

La paradójica equiparación de lo que "debería ser" y el "ser", la esencia, es clave a la hora de justificar este tipo de ideología en oposición a una visión mecanicista, alejada del orden natural. El énfasis que el organicismo pone en las esencias sirve a los no-

7 The fundamental forms of social thought, Routledge, London, 1998, pp. 17-18. STARK explica que este segundo tipo de organicismo se remonta a Aristóteles y es retomado después por santo Tomás de Aquino, quien le infunde un sentido religioso. Ambos comparten, sin embargo, una visión teleológica de la sociedad, la cual avanza hacia la perfección (p. 18). 
ventayochistas de punto de partida para desarrollar el concepto de un carácter nacional, el cual, según Labanyi conlleva un fatalismo implícito que conduce al inmovilismo, a la parálisis ${ }^{8}$ :

El esencialismo noventayochista constituye una manifestación de la creencia mítica, analizada por Mircea Eliade, de que la historia es la consecuencia de la expulsión del paraíso. Según esto, la historia es el mal, y su fin, la recuperación del estado de perfección perdido. El pensamiento mítico conlleva una visión cíclica de la historia: en parte, por estar condenada ésta a repetir los mismos errores, pero, sobre todo, por ser un intento de borrar aquellos errores, mediante el retorno a los orígenes. O sea: la historia se define como el intento de deshacer la historia (p. 21).

Miguel de Unamuno es quizás el pensador que con más ahínco se dedicó a "deshacer la historia". En su ensayo En torno al casticismo, Unamuno establece un claro enfrentamiento entre carácter nacional del pueblo y la historia. Según Unamuno, el pueblo tiene propiedades curativas, mientras que la historia y sus instituciones son las culpables de la desunión y la decadencia de España:

El pueblo da unidad; la historia y "las castas" desunen. Pueblo como protoplasma que alimenta a los organismos celulares. Tenemos que europeizarnos y chapuzarnos en pueblo. El pueblo, el hondo pueblo, el que vive bajo la historia, es la masa común a todas las castas, es su materia protoplasmática; lo diferenciante y excluyente son las clases e instituciones históricas ${ }^{9}$.

Según la conocida metáfora que Unamuno usa para explicar la intrahistoria, el cambio histórico son las olas del mar, lo más visible por su superficialidad. La verdadera "tradición eterna" son las madréporas suboceánicas que sobreviven al cambio histórico, y representan la estabilidad, lo que permanece. El concepto de intrahistoria de Unamuno niega así el mundo cambiante de la historia y reafirma las verdades eternas, los mitos. Martín Santos, por el contrario, denuncia, a través de un discurso marcadamente paródico, la visión esencialista

8 Jo LABANYi, op. cit., p. 21, advierte que tanto los intelectuales supuestamente de izquierda (Américo Castro y Claudio Sánchez Albornoz) como los de la derecha (José Antonio Primo de Rivera) han caído en la trampa de refugiarse en la creencia en una esencia nacional.

9 En torno al casticismo, Espasa Calpe, Madrid, 1961, p. 87. 
de Unamuno. Si el pueblo es, en la visión unamuniana, regenerador, Martín Santos lo presenta como un elemento dañino que impide el desarrollo del individuo o más bien como un cáncer maligno que se extiende y termina por destruir a cada uno de los miembros de la sociedad. Si Unamuno habla de la virtus medicatrix populi (las propiedades curativas del pueblo), Martín Santos asocia al pueblo (la masa) con una enfermedad mortal.

Para Unamuno la sociedad se rige por "la doctrina del pacto", el cual representa "la razón intra-histórica de la patria, su verdadera fuerza creadora" ${ }^{10}$. No se trata de un pacto consciente basado en el interés, sino de un pacto inconsciente u orgánico, "un pacto inmanente, un verdadero pacto social intra-histórico, no formulado, que es la efectiva constitución interna de cada pueblo"11. Para Martín Santos, en cambio, la relación individuosociedad se rige por la represión y la voluntad de poder. La ciudad de Madrid, que representa por metonimia la totalidad de la sociedad española, no es una comunidad formada por individuos que refuerzan su identidad al formar parte del organismo total, sino una sociedad regida por instituciones (cárcel, orfelinato, comisaría, manicomio) que sirven para regular y controlar al individuo:

Podremos comprender también que la ciudad piensa con su cerebro de mil cabezas repartidas en mil cuerpos aunque unidas por una misma voluntad de poder merced al cual los vendedores de petardos de grifa, los hampones de las puertas traseras de los conventos, los aprovechadores del puterío generoso... quedan incluidos en una esfera radiante no lecorbusiera, sino radiante por sí misma, sin necesidad de esfuerzos de orden arquitectónico, radiante por el fulgor del sol y por el resplandor del orden tan graciosa y armónicamente mantenido... que el hombre puede sufrir o morir pero no perderse en esta ciudad... porque mil, diez mil, cien mil pares de ojos lo clasifican y disponen, lo reconocen y abrazan, lo identifican y salvan, le permiten encontrarse cuando más perdido se creía en su lugar natural: en la cárcel, en el orfelinato, en la comisaría, en el manicomio, en el quirófano de urgencia ${ }^{12}$.

Unos años más tarde, Michel Foucault reflexionó en Discipline and punish: The birth of the prison ${ }^{13}$ sobre la trampa de la

10 España y los españoles, A. Aguado, Madrid, 1955, p. 189.

11 En torno al casticismo, p. 39.

12 Tiempo de silencio, Seix Barral, Barcelona, 1970, p. 17. Cito por esta edición.

13 Pantheon Books, New York, 1977. 
visibilidad. Foucault compara a la sociedad moderna con el "panopticon", un diseño de prisión en el que un solo guardia controla a los prisioneros, observándolos sin ser visto. La sociedad moderna usa una serie de instituciones, mencionadas por Martín Santos, para vigilar a los individuos y para someterlos a sus sistemas de poder y conocimiento. Al igual que Foucault, Martín Santos denuncia conceptos esencialistas de la naturaleza del sujeto y pone en un primer plano las distintas prácticas discursivas que contribuyen a la construcción de la identidad (individual y nacional). Ambos son conscientes de que una visión organicista de la sociedad tiene peligrosas ramificaciones políticas. Foucault advierte que el organicismo del siglo XIX, al postular la existencia de causas naturales subyacentes, legitima los nuevos discursos de control social que acompañan a un aparato estatal cada vez más centralizado y que se encargan de controlar ideológicamente a los ciudadanos. Según dichos discursos, lo natural, localizado en el cuerpo humano, es una esencia pre-existente que hay que conservar. En la epistemología propuesta por Foucault, en cambio, se pone en un primer plano que las esencias no son inherentes, sino construidas.

Cuando los noventayochistas promueven el cambio y la recuperación del cuerpo enfermo de España, en principio se podría pensar en su progresismo. No obstante, si analizamos a fondo los ensayos de estos pensadores (Costa, Ganivet, Unamuno y Ortega), nos damos cuenta de que en realidad muchos de ellos adoptaron posturas antidemocráticas y antiliberales. Las contradicciones que subyacen a sus planteamientos justifican el apelativo de "anarcoaristócratas" (p. 39) con que Gonzalo Sobejano $^{14}$ los califica. Esta crítica estéril que no conlleva a la acción es una postura estetizante y evasiva "típica de los falsos realistas que se sustraen de la realidad (en las soluciones propugnadas) en aras de su ideal"15.

Poco después de la publicación de Tiempo de silencio, el propio Martín Santos expresa públicamente su opinión sobre autores como Baroja y Unamuno, a quienes critica por su falta de compromiso político y por "su gran confusión mental"16 en

14 "Nietzsche y el individualismo rebelde", en Modernismo y 98. Historia y crítica de la literatura española, ed. J. C. Mainer, Crítica, Barcelona, 1980.

${ }^{15}$ Jorge Novella SuÁrez, "Ángel Ganivet y su España filosófica contemporánea”, Anales del Seminario de Historia de la Filosofía, 19 (2002), p. 248.

16 "Baroja-Unamuno", Sobre la generación del 98. Homenaje a don Pepe Villar, Editorial Auñamendi, San Sebastián, 1963, p. 109. 
cuanto a los remedios que proponen para mejorar la situación de crisis. A su vez, Jo Labanyi subraya la paradójica postura ideológica de los noventayochistas frente al franquismo:

Los escritores del 98 pudieron formar la base de una línea de oposición al franquismo, y al mismo tiempo ser la fuente de la ideología oficial del régimen, no sólo a causa de las vicisitudes políticas de los años 40, sino también a causa de la confusión que Martín-Santos, con razón, observa en sus ideas (p. 18).

Sin embargo, según Labanyi, el legado más nocivo de estos autores radica en su esencialismo y en su intento de disociar el carácter nacional del fracaso histórico: "Ni siquiera se puede decir realmente que consideran el carácter nacional como causa de la historia del país: más bien intentan demostrar que es la causa de lo bueno, y no de lo malo" (p. 19).

\section{De Costa a Unamuno: el cirujano de hierro Y LA VIRTUX MEDICATRIX POPULI}

Joaquín Costa (1844-1911), uno de esos políticos de finales del siglo xix calificados con el ambiguo término de "regeneracionista", es explícito en la concepción de la nación como un cuerpo enfermo al que hay que sanar ${ }^{17}$. En Oligarquía y caciquismo, Costa propone aplicar "una verdadera política quirúrgica" realizada por un "cirujano de hierro" (p. 115) que lleve a cabo una intervención de urgencia. Esta sugerente metáfora de Costa dio lugar a una gran polémica aún no resuelta. Para unos, Costa legitima, aun sin pretenderlo, a dos futuros dictadores españoles: Primo de Rivera y Francisco Franco ${ }^{18}$. Para otros, el mensaje progresista de Costa fue en realidad malinterpretado. En el prólogo a Ideario de Joaquín Costa ${ }^{19}$, Luis de Zulueta opina

17 JoAquín Costa hace uso de metáforas orgánicas incluso en sus ensayos literarios. En "Génesis y desarrollo de la poesía popular" se vale del análisis "biológico-literario" (Oligarquía y caciquismo, p. 143) para rebatir la existencia de la creación colectiva en la poesía popular (pp. 139-151).

18 Ésta es la interpretación del ensayista y novelista FrANCISCO UMBRAL, quien en La leyenda del César Visionario, Seix Barral, Barcelona, 1992, p. 54, se manifiesta sin ambages al respecto: "Costa y Ganivet, dos intelectuales mediocres y prefascistas, habían legitimado, sin saberlo, a todos los futuros dictadores".

19 Ed. José García Mercadal, Biblioteca Nueva, Madrid, 1935, pp. 4-16. 
que el político regeneracionista era en realidad un idealista que veía la buena voluntad del pueblo "sencillo, recto, abnegado, pero perdido por sus directores; el buen vasallo que, como el Cid, no había un buen Señor" (p. 12). El "cirujano de hierro" de Costa no debía ser un dictador, sino un dirigente compasivo, un hombre superior y providencial que conociera bien la anatomía del pueblo español.

En Tiempo de silencio, Pedro es la encarnación paródica de ese hombre superior y providencial, la figura mesiánica que llevará a cabo la regeneración de la patria. La mordacidad de Martín Santos se trasluce detrás de los apelativos con que otros personajes se refieren a él: "investigante señor" (p. 27), "el preferido, el mimado, el único" (p. 35), "un sabio de verdad” (p. 124). Desde el principio de la novela, Pedro es presentado como un científico que investiga las causas del cáncer, pero también las del mal de España. Sus reflexiones antropológicas e históricas son especialmente visibles en los primeros fragmentos de la novela, donde la voz del narrador superomnisciente se confunde en múltiples ocasiones con los pensamientos de Pedro. Su vocación mesiánica como redentor de la humanidad contra "el supremo mal" (p. 25) es retomada después en sentido literal y figurado a lo largo de toda la novela. Martín Santos parodia la imagen del "cirujano de hierro" al presentar la pusilanimidad y falta de voluntad de Pedro, quien pasa de ser un investigador admirado y respetado que aspira a conseguir el premio Nobel, a convertirse (se deja entender que ni siquiera por mérito propio) en "un discreto cirujano" (p. 211). El "discurso inevitable" (p. 209) que el director del centro de investigación le da a Pedro para comunicarle su expulsión, tiene puntos en común con la idea costista del carácter mesiánico del "cirujano de hierro" y su ascetismo. El director habla de la profesión de investigador como "un sacerdocio" (p. 210) que requiere el seguimiento de "un noble ideal" del que Pedro queda finalmente excluido ${ }^{20}$.

Tiempo de silencio es la historia de un fracaso y el periplo de Pedro por Madrid termina siendo un descenso a los infiernos. El idealismo con que busca la cura del cáncer, y también una mejor comprensión de la sociedad que le rodea, desemboca en una absoluta posición nihilista. Pedro se presenta al principio

${ }^{20}$ LABANYi, op. cit., p. 24, observa que la alusión a la profesión de investigador como sacerdocio, parodia el concepto orteguiano de la vocación y añade que la "creencia de Ortega en la propia misión divina se satiriza, al estar representado éste en el macho cabrío infernal de Goya”. 
como una especie de Quijote idealista que va a contracorriente, al investigar algo que ya ha sido investigado, pero que no pierde las esperanzas de que ocurra el milagro: "yo sólo intento demostrar si en la herencia de las cepas de ratones cancerígenos hay una transmisión dominante o si influyen más los factores ambientales. En realidad no es muy original. Ya hay algunos americanos que lo han estudiado antes que yo pero..." (p. 124). Pedro, el cerebro del cuerpo social, es pues ineficaz como investigador, y también como médico, ya que no es capaz de salvar a Florita. Tampoco demuestra tener mucha inteligencia cuando intenta defenderse al ser acusado de homicidio y su falta de control queda puesta de manifiesto cuando cae en la trampa que le tiende la abuela de Dorita. Sus instintos triunfan sobre su capacidad de raciocinio.

Como muchos de los noventayochistas, Pedro comienza con un empeño por encontrar soluciones y termina fracasado, abrumado por una gran confusión mental y finalmente sucumbiendo a la inacción, a la anulación de la voluntad. Sin embargo, como veremos más adelante, mientras los noventayochistas afirman posiciones esencialistas y fatalistas, Martín Santos responsabiliza a cada individuo de sus errores. La causa del fracaso de Pedro no está en la inferioridad racial de los españoles, ni en las difíciles circunstancias en que se ve obligado a llevar a cabo su investigación, sino en sus propias decisiones erradas.

Martín Santos pudiera estar parodiando también la confusión ideológica reinante en algunos de los ensayos de Costa. En uno de ellos, "Juan Corazón", se ofrece un breve recorrido por los numerosos estudios publicados por diversos historiadores, naturalistas, sociólogos y otros intelectuales españoles y extranjeros sobre la rápida decadencia del imperio español. Cita, por ejemplo, la teoría del "glorioso naturalista Carlos R. Darwin" para quien la razón de la decadencia hay que buscarla en "el celibato eclesiástico y la intolerancia religiosa, en los autos de fe y los calabozos de la Inquisición, que habían privado de su parte más escogida a la nación" (p. 163). También menciona Costa similares teorías del filósofo y sociólogo francés Alfredo Fouillée, según el cual la decadencia es debida a "la falta de una élite intelectual y moral, de una aristocracia natural, que no pudo formarse a causa del exceso de los conventos, la conquista de América y el Santo Oficio". Costa termina desechando estas teorías basadas en el medio ambiente y las circunstancias históricas para darnos una visión totalmente esencialista: "Yo 
me inclino a pensar que la causa de nuestra inferioridad y de nuestra decadencia es étnica y tiene su raíz en los más hondos estratos de la corteza del cerebro" (p. 164). Costa encuentra apoyo para sus propuestas en las teorías antroposociológicas del inglés Ammon y el francés Lapouge, quienes en 1896 distinguen tres tipos de seres humanos en Europa: "el homo europaeus (el tipo superior), el alpinus y el mediterraneus (el inferior de los tres)" (p. 165). Estas tres razas se diferenciarían, según Costa, tanto por su físico como por sus cualidades espirituales. Los españoles deben luchar contra el destino de su raza, eliminando lo que en ellos hay de homo mediterraneus y sustituyéndolo por las características raciales superiores del homo europaeus. Costa termina proponiendo una solución peregrina, con una estructura sintáctica también peregrina, en la que -al igual que en muchos pasajes de Tiempo de silencio- se suceden las subordinadas condicionales, sin llegar nunca a la cláusula principal:

Si la hipotética jerarquía se confirma como natural, no como meramente histórica, y resulta en definitiva que esa falta de aptitudes de gobierno en los españoles y la consiguiente decadencia de la nación desde que se hizo necesaria una mayor capacidad psíquica para los nuevos horizontes abiertos por el Renacimiento, la crisis religiosa y la constitución de las nacionalidades, tiene un fundamento natural en las circunvoluciones cerebrales, el problema de los problemas para nosotros, en su aspecto positivo, práctico, quedará siendo sencillamente éste: si el homo mediterraneus puede descender $[s i c]$ en la escala de la mentalidad al grado de homo europaeus, si esa causa de nuestra inferioridad, no obstante su condición de natural, puede ser removida, y removida por iniciativa y acción propia; y, en suma, si existe posibilidad de dotar al español de una cabeza nueva... sea por arte de física y de fisiología, el día que se logre crear una neurocultura, que sea respecto de las neuronas, dendrites, fibras de proyección, etcétera, de la substancia gris del cerebro lo que la filotecnia o agricultura es respecto de las plantas, ora por vía selectiva, tomando como base en nuestro subsuelo étnico la porción del homo europaeus que parece hay en la Península, mezclada con la mayoría de los restantes tipos occidentales, ora por puro influjo exterior, afinado y forzando la pedagogía tradicional, en la manera que acaban de acreditar tan brillantemente los nipones (p. 165).

La falta de lógica del argumento de Costa es patente. Si bien apunta al principio del ensayo que la decadencia de España es debida a causas históricas, termina deslizándose hacia la esfera 
de las esencias. En un arranque de irracionalidad, Costa niega la historia y habla de la inferioridad natural de los españoles. Sin embargo, espera superar esa inferioridad, no mediante acciones y propuestas claras de desarrollo, sino a través de una milagrosa adquisición de características raciales superiores. De forma similar, Pedro en Tiempo de silencio, sabe que las causas del tipo de cáncer que investiga, como ya han probado otros científicos extranjeros, son genéticas y aunque está convencido de la inutilidad de su empresa, la continúa porque ha asumido su papel de redentor de la humanidad. Es más, mediante la alusión a la cepa de ratones que Pedro usa para su investigación, el narrador reflexiona con ironía sobre la forma en que los conocimientos sobre genética pueden terminar usándose con una finalidad opuesta a la de su concepción original: en vez de perseguir "la extirpación de todo mal hereditario", se ha creado "una raza en que lo execrable es constante" (p. 12). La conexión con el discurso de la eugenesia desarrollado a principios del siglo $\mathrm{xx}, \mathrm{y}$ también durante el franquismo, no puede pasar desapercibida.

En el monólogo interior que abre la novela, Pedro reflexiona sobre la proverbial inferioridad de los españoles para la ciencia y hace alusión a estas supuestas limitaciones biológicas: “¿Cómo podremos nunca [ser buenos científicos], si además de ser más torpes, con el ángulo facial estrecho del hombre peninsular, con el peso cerebral disminuido por la dieta monótona por las muelas, fabes, agarbanzadas leguminosas y carencia de prótidos?” (p. 8). El monólogo continúa explorando la idea de la inferioridad racial de los españoles y comparando sus carencias dietéticas con la buena alimentación de "las rubias mideluésticas mozas con proteína abundante" (p. 9). Las ideas aparecen de forma desordenada y confusa, dispersas en una sintaxis casi tan enrevesada como la de Costa y presentadas a través del fluir de conciencia de un hombre que lamenta la falta de recursos para la investigación, pero que fantasea, a pesar de todo, con conseguir el premio Nobel y ser capaz de demostrar ante el mundo que la transmisión del cáncer no es genética, sino vírica y que la supuesta inferioridad de los españoles tampoco es heredada, sino causada por limitaciones ambientales (carencias alimenticias y materiales para llevar a cabo la investigación). Habría por tanto esperanza de sanar la nación, pero Pedro ve obstruida su misión salvadora por la intervención del Otro, el pueblo, la masa. Martín Santos parodia el modelo organicista al 
presentar la cabeza del cuerpo social (Pedro) fagocitada por el resto de los organismos (el pueblo). Si Unamuno nos invita a "chapuzarnos en pueblo", Martín Santos presenta a Pedro, al final de la novela, "rodeado de pueblo por delante, por detrás, por arriba, por abajo, frente al pueblo sublimado del escenario, bajo el pueblo ululante del gallinero, ante el pueblo vergonzante de las filas de atrás". Se siente, además, físicamente invadido, atacado por "la gran carcajada colectiva" que penetra "a través del cráneo duro y de la masa encefálica cuajada de neuronas estudiosas" (p. 225). La disociación entre el todo (la sociedad) y las partes (en este caso Pedro, como individuo) aparece aquí de forma patente. Pedro no funciona en armonía con el resto del organismo de que forma parte.

El pueblo es, en la visión unamuniana, un organismo vivo donde se encuentra la clave de la regeneración de cada uno de los individuos: "De ahí que el proyecto regenerador de Unamuno en En torno al casticismo consista en una propuesta de reintegración del país a sus raíces orgánicas e intrahistóricas, de las que se ha desviado, apartándose de su propio ser" ${ }^{21}$. Según Unamuno, para llegar a encontrar el propio ser (el carácter nacional verdadero) no se puede dividir la totalidad en un todo y unas partes, puesto que "el aislamiento de una parte con respecto al todo lleva a la muerte de la parte; de la misma manera que un individuo gana su identidad en el Volkgeist en el que se integra, y sin formar parte de ese espíritu no puede llegar a ser un ser humano plenamente desarrollado" 22 . Para el Unamuno de En torno al casticismo, el remedio al mal del España está en el pueblo, en el "espíritu colectivo intracastizo" (p. 303). Unos años después, Unamuno se lamenta de nuevo de que España sigue enferma porque "no se muestra fe alguna en las virtus medicatrix populi, en la vitalidad orgánica de nuestro pueblo, ni se alienta tranquila esperanza en su sufrida calma" ${ }^{23}$.

Martín Santos, por el contrario, presenta una visión muy distinta del pueblo español, especialmente cuando describe al público del espectáculo de variedades como "el buen pueblo acumulado, sentado, apretado, sudante, oprimiente-oprimido", totalmente ajeno a "sus enajenaciones y conmovido en las fibras más íntimas de un orgullo condescendiente, [que] admite en voz baja -pero sincerísima- que vivan-las-caenas" (p. 222). El

${ }^{21}$ La Rubia Prado, op. cit., p. 50.

22 Ibid., p. 55.

23 España y los españoles, p. 68. 
pueblo es presentado, al igual que lo hiciera Unamuno, como un organismo vivo, pero el pueblo de Tiempo de silencio parece encontrar su genuina identidad en la opresión. De ahí que la alusión al grito popular de adhesión a Fernando VII, a su vuelta del destierro, constituya una crítica velada a la sociedad española de la posguerra, una sociedad acomodaticia y satisfecha con las cadenas del régimen autoritario franquista. Lo que une al pueblo español es una carcajada colectiva de inconsciencia ("vivan las caenas") que refleja el "feliz proceso de adaptación" (p. 224) a una situación de hambre, opresión, abusos, escarnios y falta de libertad.

Si para Unamuno el pueblo es la materia protoplasmática que alimenta las células, para Martín Santos, las células cancerígenas del tejido social invaden, desplazan y destruyen los tejidos sanos. Unamuno afirma la unidad y Martín Santos la cuestiona, puesto que dicha unidad ni es natural ni da vida; por el contrario, silencia y paraliza. El último fragmento de Tiempo de silencio es una clara crítica de la mistificación que Unamuno hace del campo castellano y de su contribución a la formación física y espiritual de la vida intrahistórica. Pedro no encuentra en la meseta castellana, la base de la vida, sino más bien un "museo anatómico de vivos" donde le han colgado "para que sienta bien las cualidades empirreumáticas e higiénicas, disecadoras y esterilizadoras, atrabiliagenésicas y justicieras del hombre de la meseta, de este tipo de hombre de la meseta que hizo historia" (p. 236) ${ }^{24}$. Este hombre de la meseta que Unamuno definiera como "una casta de complexión seca, dura y sarmentosa, tostada por el sol y curtida por el frío" (p. 214) es retomado por Martín Santos con el sarcasmo que le caracteriza para criticar no sólo las visiones esencialistas de Unamuno, sino también para referirse a la negación del franquismo de un período de la historia de España que se extiende desde los comienzos del declive del imperio español hasta finales de la guerra civil: "y ahora, reseco y carcomido, amojamado hombre de la meseta, puesto a secar como yo mismo para que me haga mojama en los buenos aires castellanos, donde la idea de lo que es futuro se ha perdido hace tres siglos y medio y el futuro ya no es sino la carcomida marronez que va tomando un cuerpo de buey

${ }^{24}$ Las contradicciones y paradojas unamunianas quedan parodiadas al final de Tiempo de silencio cuando Pedro se lamenta de su incapacidad de actuar: "Estoy desesperado de no estar desesperado. Pero podría también no estar desesperado a causa de estar desesperado por no estar desesperado" (p. 240). 
puesto a secar" (p. 236). La expresión que Estrabón utiliza para referirse a España ha sido traducida habitualmente como "piel de toro", pero Martín Santos evita la connotación de virilidad (una virtud ensalzada por la Falange) al usar una traducción también posible, "piel de buey". Parodiando la visión organicista de la nación, Martín Santos presenta a Pedro no como miembro de un organismo vivo, sino como parte de una piel de buey (un toro castrado), castrado también él, un eunuco que se amojama en silencio (pp. 238-239).

En conclusión, en Tiempo de silencio se presenta "el mal de España" desde una óptica muy distinta a la de los escritores finiseculares. Si éstos se preocuparon por diagnosticar y proponer una cura para dicho mal, Martín Santos a través de la parodia y la ironía, presenta la realidad española y su historia con todas sus contradicciones, pero sin ofrecer recetas mágicas. Martín Santos parodia las metáforas orgánicas de los escritores finiseculares y deja patente su "mezcla de esencialismo y existencialismo, idealismo y positivismo, estoicismo y egoísmo, nostalgia por lo primitivo y repugnancia por el retraso, odio a las masas y amor por el pueblo" 25 . Por su parte, no resuelve estas contradicciones en su novela, sino que se limita a ponerlas en evidencia mediante un magistral uso del realismo dialéctico, así como el juego irónico y paródico. El mundo presentado en Tiempo de silencio "es el resultado de la vida y el pensamiento de siglos anteriores, cuyo quehacer explica la fisonomía del momento presente" ${ }^{26}$. La forma en que Martín Santos reflexiona sobre la identidad nacional y la circunstancia concreta de la España de los años cuarenta y cincuenta está condicionada por los intelectuales que le preceden, de quienes se nutre su discurso y a quienes parodia de forma sutil, pero eficaz. El final de Tiempo de silencio es desolador y se podría recriminar a Martín Santos de ser artífice de una visión tan pesimista como la que critica. Sin embargo, esta novela no es tanto una visión desesperanzada como un grito de protesta contra la abulia y apatía acomodaticia de los españoles durante los años del silencio.

María Asunción Gómez Florida International University

${ }^{25}$ Jo Labanyi, op. cit., p. 18.

26 Alfonso Rey, Construcción y sentido de "Tiempo de silencio", J. Porrúa Turanzas, Madrid, 1977, p. 211. 
